\title{
Clinical, physiologic, and radiographic factors contributing to development of hypoxemia in moderate to severe COPD: a cohort study
}

J. Michael Wells ${ }^{1,2,3,12^{*}}$, Raul San Jose Estepar ${ }^{4}$, Merry-Lynn N. McDonald ${ }^{5}$, Surya P. Bhatt ${ }^{1,2}$, Alejandro A. Diaz ${ }^{6}$, William C. Bailey ${ }^{1,2}$, Francine L. Jacobson ${ }^{4}$, Mark T. Dransfield ${ }^{1,2,3}$, George R. Washko ${ }^{6}$, Barry J. Make ${ }^{7}$, Richard Casaburi ${ }^{8}$, Edwin J. R. van Beek ${ }^{9}$, Eric A. Hoffman ${ }^{10}$, Frank C. Sciurba ${ }^{11}$, James D. Crapo ${ }^{7}$, Edwin K. Silverman ${ }^{5}$, Craig P. Hersh ${ }^{5}$ and the COPDGene Investigators

\begin{abstract}
Background: Hypoxemia is a major complication of COPD and is a strong predictor of mortality. We previously identified independent risk factors for the presence of resting hypoxemia in the COPDGene cohort. However, little is known about characteristics that predict onset of resting hypoxemia in patients who are normoxic at baseline. We hypothesized that a combination of clinical, physiologic, and radiographic characteristics would predict development of resting hypoxemia after 5 -years of follow-up in participants with moderate to severe COPD
\end{abstract}

Methods: We analyzed 678 participants with moderate-to-severe COPD recruited into the COPDGene cohort who completed baseline and 5-year follow-up visits and who were normoxic by pulse oximetry at baseline. Development of resting hypoxemia was defined as an oxygen saturation $\leq 88 \%$ on ambient air at rest during follow-up. Demographic and clinical characteristics, lung function, and radiographic indices were analyzed with logistic regression models to identify predictors of the development of hypoxemia.

Results: Forty-six participants (7\%) developed resting hypoxemia at follow-up. Enrollment at Denver (OR 8.30, 95\% Cl 3.05-22.6), lower baseline oxygen saturation (OR 0.70,95\% Cl 0.58-0.85), self-reported heart failure (OR 6.92, $95 \% \mathrm{Cl} 1.56-30.6)$, pulmonary artery (PA) enlargement on computed tomography (OR 2.81,95\%Cl 1.17-6.74), and prior severe COPD exacerbation (OR 3.31,95\%Cl 1.38-7.90) were independently associated with development of resting hypoxemia. Participants who developed hypoxemia had greater decline in 6-min walk distance and greater 5 -year decline in quality of life compared to those who remained normoxic at follow-up.

Conclusions: Development of clinically significant hypoxemia over a 5-year span is associated with comorbid heart failure, PA enlargement and severe COPD exacerbation. Further studies are needed to determine if treatments targeting these factors can prevent new onset hypoxemia.

Trial registration: COPDGene is registered at ClinicalTrials.gov: NCT00608764 (Registration Date: January 28, 2008)

*Correspondence: jmwells@uabmc.edu

1 Division of Pulmonary, Allergy, and Critical Care Medicine, University of

Alabama Birmingham, Birmingham, AL, USA

${ }^{2}$ Lung Health Center University of Alabama Birmingham, Birmingham, AL,

USA

Full list of author information is available at the end of the article 


\section{Background}

Hypoxemia is a major complication of chronic obstructive pulmonary disease (COPD) and is associated with increased mortality [1] and impaired exercise tolerance [2]. Hypoxemia contributes to other COPD-related complications including pulmonary vascular disease [3], skeletal muscle dysfunction [4], and polycythemia [5]. Resting hypoxemia has major implications related to morbidity, therapy, and prognosis, unlike exercise induced desaturation and nocturnal desaturation in COPD which have less welldefined prognostic significance [6-9]. The Centers for Medicare and Medicaid Services (CMS) defines the clinical threshold for hypoxemia in stable COPD as arterial oxygenation $\left(\mathrm{PaO}_{2}\right) \leq 55 \mathrm{mmHg}$ or pulse oximetry $\left(\mathrm{SpO}_{2}\right)$ $\leq 88 \%$ [10-12]. Treatment of resting hypoxemia with supplemental oxygen therapy is one of the few therapies for COPD that improves quality of life, exercise tolerance, and mortality [13-15]; thus, it is important to identify risk factors for its development.

Previously, in cross sectional analyses, we demonstrated that female sex, increased body mass index (BMI), lower forced expiratory volume in 1-s $\left(\mathrm{FEV}_{1}\right)$, and high altitude (Denver, altitude $5280 \mathrm{ft}$ ) were independently associated with resting oxygen saturation of $\leq 88 \%$ on ambient air [16]. However, there is a paucity of information regarding the development and impact of new onset hypoxemia in COPD. Therefore, we hypothesized that a combination of clinical, physiologic, and radiographic characteristics would predict development of resting hypoxemia after 5 -years of follow-up in participants with moderate to severe COPD. Further, we hypothesized that incident hypoxemia would be associated with negative impacts on quality of life, exercise performance, and lung function.

\section{Methods}

\section{Subject selection}

COPDGene is a prospective observational study conducted at 21 clinical centers across the U.S., including
National Jewish Hospital in Denver [17]. In Phase 1, COPDGene recruited 10,192 non-Hispanic white and African-American current and former smokers (10 or more pack-years) 45 years old or older with and without COPD [17]. Participants are now returning for a Phase 2 visit approximately 5-years after their original visit. All study participants were at baseline health status, defined as no AECOPD within the previous 4 weeks, no surgery, acute myocardial infarction, or hospitalization for a cardiac problem within the previous 3 months, to standardize conditions between Phase 1 and Phase 2 visits. Our analysis used an interim dataset of the first 2000 Phase 2 participants. We included participants with moderate to very severe COPD defined by Global Initiative for Chronic Obstructive Lung Disease (GOLD) [18] spirometry grade 2-4 COPD at Phase 1, who did not have resting hypoxemia at baseline. COPDGene was approved by the Institutional Review Boards at participating institutions (Additional file 1: Table S1, online supplement).

\section{Oxygen saturation measurement}

Oxygen saturation was measured by pulse oximetry on ambient air at both visits [17]. Pulse oximetry was obtained with the subject in the seated position and the value was recorded after the subject remained at rest in the seated position for at least $5 \mathrm{~min}$. The pulse oximeter was placed on a finger without nail polish. The median value obtained while observing the monitor over a 1-min observation period was recorded. Pulse oximeters were calibrated on a regular basis on a schedule determined by the manufacturer's recommendation and the local clinical center bioengineering department. Study coordinators were adequately trained in measurement in pulse oximetry. If participants used supplemental oxygen, oxygen was discontinued for $5 \mathrm{~min}$ prior to measurement of pulse oximetry. If the oxygen saturation fell below $82 \%$, supplemental oxygen was restarted and $82 \%$ was recorded

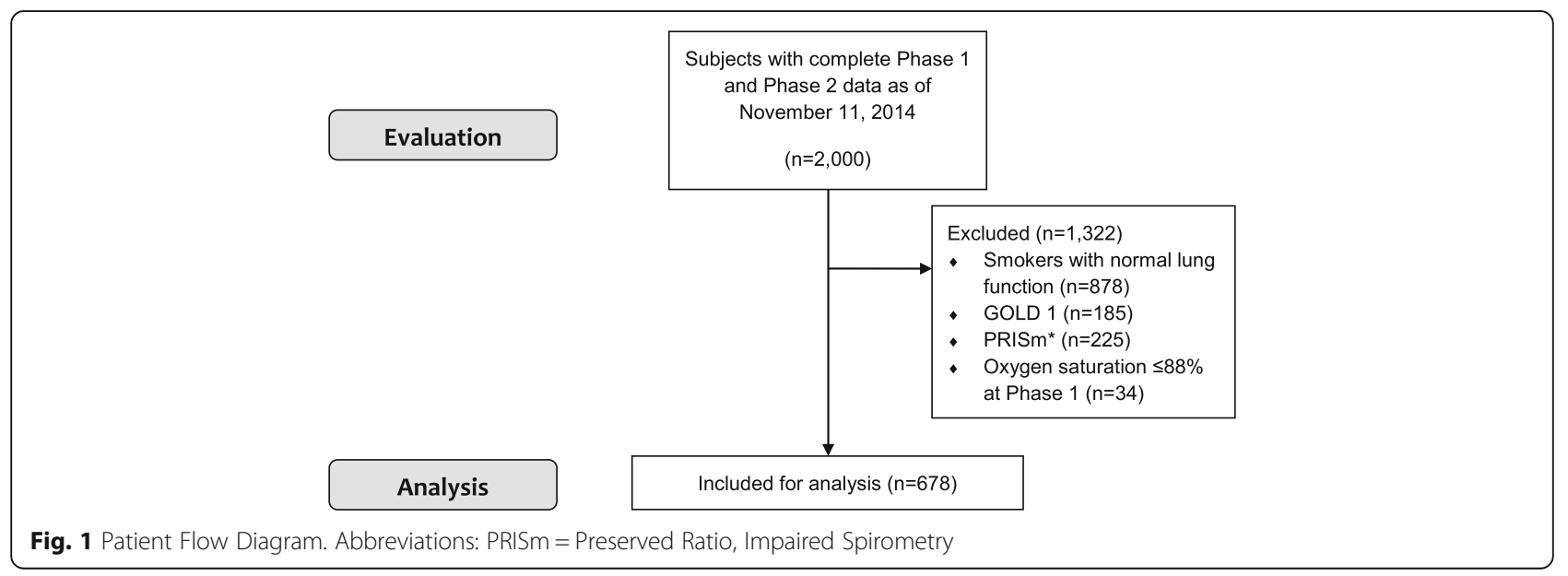


as the resting value. Hypoxemia was defined as an oxygen saturation $\leq 88 \%$ on ambient air $[13,14]$.

\section{Study procedures}

Both visits included spirometry before and after 2 puffs of albuterol [19], 6 min walk testing (6MWT) [20], and the St. George's Respiratory Questionnaire (SGRQ) [21], a measurement of quality of life (higher scores indicate worse quality of life) and the modified medical research council (MMRC) [22] dyspnea score. Comorbidities were defined by subject self-report. Coronary artery disease was defined as a positive response to history of coronary artery disease, angina, myocardial infarction, percutaneous coronary intervention, or coronary artery bypass graft surgery.

\section{Imaging}

Participants underwent inspiratory and expiratory computed tomography $(\mathrm{CT})$ scans of the chest at the baseline visit [17]. Emphysema was quantified by the percent of low attenuation areas (\%LAA) $<-950 \mathrm{HU}$ on full inspiration [23] and gas trapping was quantified by \%LAA $<-856 \mathrm{HU}$ at relaxed expiration [24] using Slicer software (www.slicer.org). The pulmonary artery (PA) and ascending aorta (A) diameters were measured as previously reported; a PA/A ratio $>1$ indicated PA enlargement $[25,26]$.

\section{Statistical analysis}

Hypoxemia was defined by a resting $\mathrm{O}_{2}$ saturation $\leq 88 \%$ measured at the Phase 2 visit. Univariable logistic regression was used to define associations between Phase 1 variables and the development of hypoxemia at Phase 2 . Variables associated at alpha $<0.10$ on univariable analysis were entered into a multivariable backward logistic regression model to include all potential factors associated with hypoxemia at phase 2 . Given the large percent of individuals recruited from the Denver site and the expected impact of living at altitude, we performed a sensitivity analysis using the multivariable logistic regression model on the subgroup of participants not recruited in Denver. T-tests were used to analyze differences in outcome measures (change in SGRQ, MMRC, 6MWT, and $\mathrm{FEV}_{1}$ ) between those who did and did not develop hypoxemia. Significance was defined as a $P<0.05$. Analysis used SPSS for Windows Version 23 (IBM, USA).

\section{Results}

\section{Subject characteristics}

Of the 2000 participants who completed Phase 2 visits, $n=678$ met inclusion criteria (Fig. 1). As seen in Table 1, participants were $63 \pm 8$ years old at Phase $1,77 \%$ were non-Hispanic white, and $55 \%$ were male with a predicted $\mathrm{FEV}_{1}$ of $54 \pm 16 \%$. A total of $132(19 \%)$ individuals were enrolled in Denver. At baseline, heart rate was $76 \pm 12$ beats $/ \mathrm{min}$ and oxygen saturation was $95.5 \pm 2.4 \%$. Selfreported comorbid conditions included coronary artery disease (15\%), congestive heart failure (3\%), diabetes (11\%), sleep apnea (20\%), thromboembolic disease (4\%), peripheral vascular disease (3\%), and cerebrovascular disease (5\%). On CT imaging, mean percent emphysema was 12.7 $\pm 11.7 \%$, gas trapping was $38 \pm 19 \%$, and $19 \%$ of participants had a PA/A ratio $>1$.

Table 1 Baseline characteristics from Phase 1

\begin{tabular}{|c|c|}
\hline Variable & $n=678$ \\
\hline Age, years & $63 \pm 8$ \\
\hline Non-Hispanic white race & $525(77 \%)$ \\
\hline Male sex & $375(55 \%)$ \\
\hline Enrollment at Denver clinical site & $132(19 \%)$ \\
\hline $\mathrm{BMI}, \mathrm{kg} / \mathrm{m}^{2}$ & $28.2 \pm 5.8$ \\
\hline Baseline heart rate, beats/min & $76 \pm 12$ \\
\hline Baseline oxygen saturation, \% & $95.5 \pm 2.4$ \\
\hline Current Smokers & $248(37 \%)$ \\
\hline Pack Year History & $52 \pm 26$ \\
\hline Coronary Artery Disease & $102(15 \%)$ \\
\hline Congestive Heart Failure & $20(3 \%)$ \\
\hline Hypertension & $315(47 \%)$ \\
\hline Hyperlipidemia & $277(41 \%)$ \\
\hline Asthma & $178(26 \%)$ \\
\hline Sleep apnea & $137(20 \%)$ \\
\hline Thromboembolic disease & $26(4 \%)$ \\
\hline Peripheral vascular disease & $23(3 \%)$ \\
\hline Cerebrovascular disease & $36(5 \%)$ \\
\hline Gastroesophageal reflux disease & $215(32 \%)$ \\
\hline $\mathrm{FEV}_{1}$, percent predicted & $54 \pm 16$ \\
\hline $\mathrm{FEV}_{1} / \mathrm{FVC}$ & $0.51 \pm 0.12$ \\
\hline GOLD 2 & $405(59.7 \%)$ \\
\hline GOLD 3 & $215(31.7 \%)$ \\
\hline GOLD 4 & $58(8.6 \%)$ \\
\hline Percent emphysema, $-950 \mathrm{HU}$ & $12.7 \pm 11.7$ \\
\hline Percent gas trapping & $38 \pm 19$ \\
\hline PA/A ratio & $0.89 \pm 0.13$ \\
\hline PA/A ratio $>1$ & $127(19 \%)$ \\
\hline Severe AECOPD 1-year prior & $101(15 \%)$ \\
\hline MMRC & $1.8 \pm 1.4$ \\
\hline $\mathrm{SGRQ}$, total & $35 \pm 21$ \\
\hline $6 \mathrm{MWD}, \mathrm{ft}$ & $1277 \pm 361$ \\
\hline
\end{tabular}

Values represent mean $\pm \mathrm{SD}$ or $\mathrm{n}(\%)$

Definitions: FEV 1 forced expiratory volume in 1-s, FVC forced vital capacity, GOLD Global initiative for obstructive lung disease, $P A$ pulmonary artery, $A$ aorta, $A E C O P D$ acute exacerbation of COPD, MMRC modified medical research council, SGRQ St. George's Respiratory Questionnaire, 6MWD 6-min walk distance 


\section{Change in oxygen saturation over 5-years}

The median follow-up time was 64 (range 51-78) months. As exhibited in Fig. 2, the change in resting oxygen saturation was normally distributed with a mean decrease of $1 \%$ over the 5 -year period. Between Phase 1 and Phase 2 visits, 46 patients (7\%) of patients developed hypoxemia at Phase 2.

\section{Predictors of the development of hypoxemia at rest}

Development of a resting oxygen saturation $\leq 88 \%$ at Phase 2 was predicted by several baseline variables using univariable logistic regression (Table 2). In the multivariable model, enrollment at Denver, lower oxygen saturation at baseline, self-reported CHF, PA/A ratio $>1$, and having a severe AECOPD within 12-months prior to study entry were independently associated with the development of hypoxemia (Table 3). We observed a negative correlation between baseline CT percent emphysema and follow-up oxygen saturation $(R=-0.23, P<0.001)$. COPD cases who developed hypoxemia had higher baseline percent emphysema than those who did not develop hypoxemia $(15.8 \pm 10 \%$ versus $12.5 \pm 10 \%, P=0.015$ ), though emphysema did not independently contribute to the regression model. Percent gas trapping on $\mathrm{CT}$ was not significantly elevated in cases that developed hypoxemia compared to those who did not $(43.1 \pm 13.7 \%$ versus $37.6 \pm 19 \%, P=0.057)$.

We performed a sensitivity analysis by excluding the 132 participants ( $n=32$ who developed hypoxemia) enrolled in Denver. As demonstrated in Table 4, lower baseline oxygen saturation, CHF, and a previous severe exacerbation remained independently associated with the development of hypoxemia, mirroring findings from the entire cohort.

\section{Associations between incident hypoxemia, quality of life, and 6-min walk distance}

The development of hypoxemia adversely impacted quality of life, exercise tolerance, and dyspnea (Fig. 3). The change in total SGRQ $(8.0 \pm 2.1$ versus $1.4 \pm 0.6$ points, $P=0.003)$, activity subscore $(9.1 \pm 2.5$ versus 3.8 $\pm 0.8, P=0.05)$, and impact subscore $(8.5 \pm 2.4$ versus $0.6 \pm 0.6, P=0.002$ ) were significantly higher in COPD cases who did vs. those who did not develop resting hypoxemia. The difference in change in SGRQ symptom score was not significant $(4.2 \pm 3.1$ versus $-0.3 \pm 0.9$, $P=0.18)$. COPD cases who developed hypoxemia had a trend towards increased dyspnea (change in MMRC 0.52 \pm 0.17 versus $0.17 \pm 0.05, P=0.053$ ). We observed a 3 -fold greater decline in 6MWD $(-440 \pm 62$ versus $-141 \pm 14 \mathrm{ft}$. [-134 \pm 19 versus $-43 \pm 4 \mathrm{~m}], P<0.001)$ in participants who developed hypoxemia.

\section{Discussion}

We showed that there is substantial variability in the change in oxygen saturation over a 5-year period in non-hypoxemic participants with moderate to severe

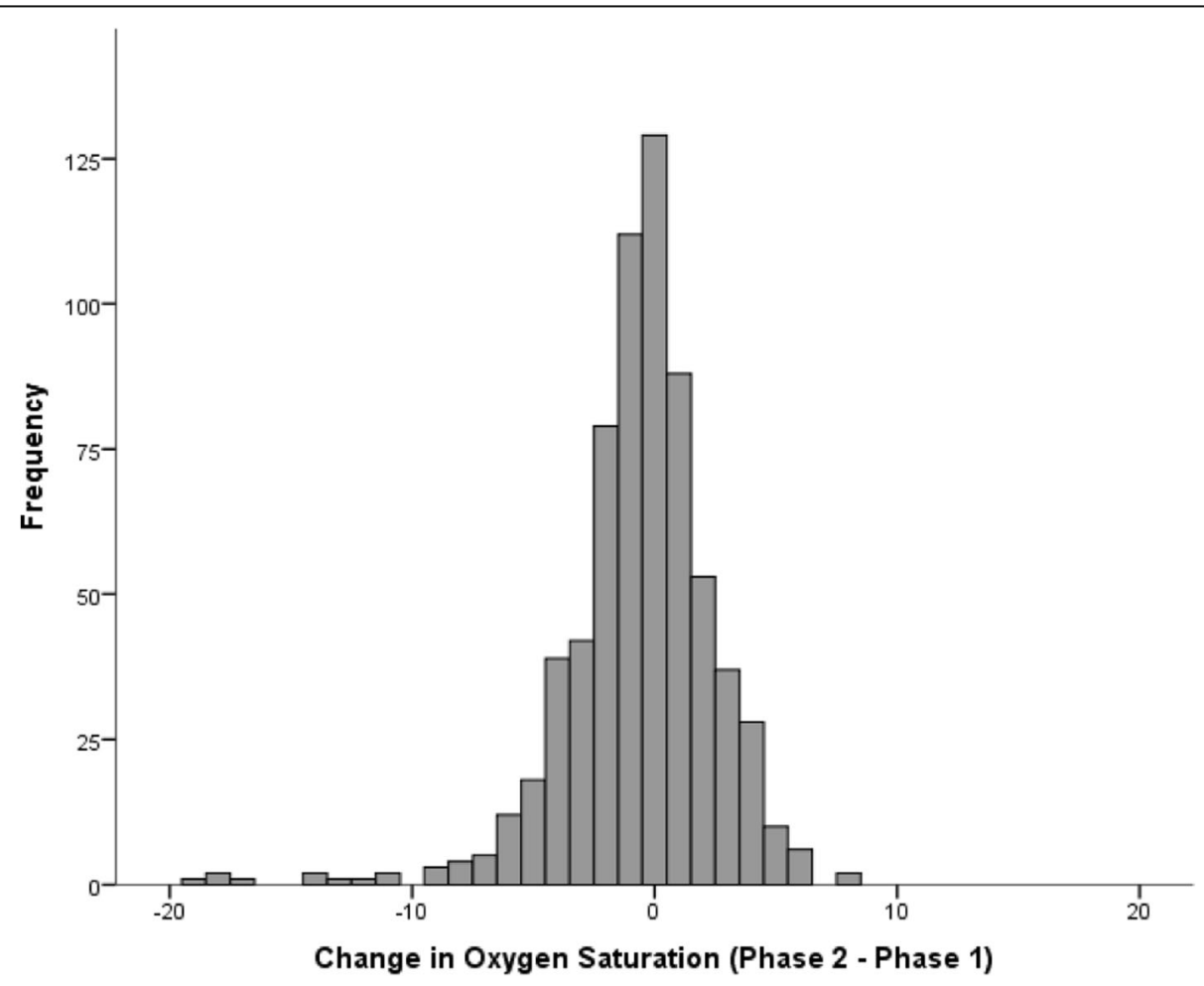

Fig. 2 Distribution of change in oxygen saturation over a 5-year period among COPD cases without hypoxemia at baseline $(n=678)$ 
Table 2 Variables associated with the development hypoxemia at rest among COPD cases

\begin{tabular}{|c|c|c|c|}
\hline Variable & OR & $95 \% \mathrm{Cl}$ & $P$-value \\
\hline Age, per 1 year increase & 1.05 & $1.01-1.09$ & 0.021 \\
\hline African American race & 3.24 & $1.14-9.18$ & 0.027 \\
\hline Male sex & 1.41 & $0.76-2.62$ & 0.28 \\
\hline Enrollment at Denver clinical site & 12.2 & $6.26-23.6$ & $<0.001$ \\
\hline $\mathrm{BMl}, \mathrm{kg} / \mathrm{m}^{2}$ & 0.98 & $0.93-1.04$ & 0.47 \\
\hline Baseline heart rate, beat/min & 1.02 & $0.99-1.04$ & 0.20 \\
\hline Baseline oxygen saturation, \% & 0.62 & $0.54-0.70$ & $<0.001$ \\
\hline Current Smokers & 0.67 & $0.34-1.29$ & 0.23 \\
\hline Pack Year History & 1.01 & $1.00-1.02$ & 0.05 \\
\hline Coronary artery disease & 1.41 & $0.66-3.02$ & 0.38 \\
\hline Congestive heart failure & 5.02 & $1.74-14.5$ & 0.003 \\
\hline Hypertension & 0.59 & $0.32-1.11$ & 0.10 \\
\hline Hyperlipidemia & 1.23 & $0.68-2.25$ & 0.49 \\
\hline Asthma & 1.28 & $0.97-1.70$ & 0.08 \\
\hline Sleep apnea & 1.28 & $0.96-1.70$ & 0.09 \\
\hline Thromboembolic disease & 1.15 & $0.26-5.02$ & 0.85 \\
\hline Peripheral Vascular Disease & 1.32 & $0.30-5.81$ & 0.71 \\
\hline Cerebrovascular Disease & 1.26 & $0.37-4.29$ & 0.71 \\
\hline Gastroesophageal reflux & 1.72 & $0.94-3.16$ & 0.08 \\
\hline $\mathrm{FEV}_{1}$, percent predicted & 0.98 & $0.96-0.99$ & 0.02 \\
\hline Percent emphysema & 1.02 & $0.99-1.05$ & 0.09 \\
\hline Percent gas trapping & 1.02 & $0.99-1.03$ & 0.09 \\
\hline $\mathrm{PA} / \mathrm{A}$ ratio $>1$ & 2.02 & $1.04-3.92$ & 0.038 \\
\hline Severe AECOPD within 12 months & 2.98 & $1.56-5.67$ & 0.001 \\
\hline
\end{tabular}

Data represents univariable associations as determined by logistic regression analysis

Abbreviations: $O R$ odds ratio, $C l$ confidence interval, $B M I$ body mass index, $F E V_{1}$ forced expiratory volume in 1-s, $F V C$ forced vital capacity, $P A / A$ pulmonary artery to aorta ratio, $A E C O P D$ acute exacerbation of chronic obstructive pulmonary disease

Table 3 Independent predictors of incident resting hypoxemia in individuals with COPD

\begin{tabular}{llll}
\hline Variable & OR & $95 \% \mathrm{Cl}$ & $P$-value \\
\hline Enrollment at Denver clinical site & 8.30 & $3.05-22.6$ & $<0.001$ \\
Baseline oxygen saturation, \% & 0.70 & $0.58-0.85$ & $<0.001$ \\
Congestive heart failure & 6.92 & $1.56-30.6$ & 0.01 \\
PA/A ratio >1 & 2.81 & $1.17-6.74$ & 0.02 \\
Severe AECOPD within 12-months & 3.31 & $1.38-7.90$ & 0.007 \\
\hline
\end{tabular}

Variables included in the backwards multivariate logistic regression model: age, race, sex, Denver, baseline oxygen saturation, pack-year history of tobacco use, congestive heart failure, hypertension, asthma, sleep apnea, gastroesophageal reflux disease, $\mathrm{FEV}_{1}$ percent predicted, percent emphysema, percent gas trapping, $\mathrm{PA} / \mathrm{A}>1$, severe AECOPD within 12 -months of visit $\left(R^{2}=0.39, P<0.001\right)$. Abbreviations: $\mathrm{OR}=$ odds ratio, $\mathrm{Cl}=$ confidence interval, $\mathrm{PA} / \mathrm{A}=$ pulmonary artery to aorta ratio, $\mathrm{AECOPD}=$ acute exacerbation of chronic obstructive pulmonary disease
Table 4 Multivariable logistic associations with the development of hypoxemia in subjects recruited from non-Denver sites

\begin{tabular}{llll}
\hline Variable & OR & $95 \% \mathrm{Cl}$ & P-value \\
\hline Baseline oxygen saturation, \% & 0.77 & $0.60-0.99$ & 0.04 \\
Congestive heart failure & 7.22 & $1.66-31.3$ & 0.008 \\
Severe AECOPD within 12 months & 4.26 & $1.33-13.6$ & 0.015
\end{tabular}

This analysis is of the subgroup $(n=546)$ not recruited at Denver. Variables included in the backwards stepwise logistic regression model: age, race, sex, baseline oxygen saturation, congestive heart failure, $\mathrm{FEV}_{1}$ percent predicted, $\mathrm{PA} / \mathrm{A}>1$, and severe AECOPD within 12-months of visit

Abbreviations: $O R$ odds ratio, $C l$ confidence interval, $B M I$ body mass index, $F E V_{1}$ forced expiratory volume in 1-s, FVC forced vital capacity, PA/A pulmonary artery to aorta ratio, $A E C O P D$ acute exacerbation of chronic obstructive pulmonary disease

COPD. Hypoxemia develops in an appreciable proportion, and we identified multiple risk factors that are associated with incident hypoxemia at rest. Modifiable risk factors include living at high altitude and COPD exacerbations, and non-modifiable risk factors include baseline oxygen saturation, comorbid $\mathrm{CHF}$, and pulmonary arterial enlargement on CT. Incident hypoxemia was associated with accelerated $\mathrm{FEV}_{1}$ decline, poorer quality of life, and shorter 6MWD.

Our results were consistent with prior analyses examining the longitudinal change in oxygen saturation and add to our understanding by adding imaging based metrics to clinical factors known to be associated with hypoxemia. In a population-based study of 2822 participants in Norway including $23.1 \%$ with COPD, Vold and colleagues reported that there was not an overall change in mean oxygen saturation over 6.3 years [27]. Only 25 participants $(0.9 \%)$ in their study developed an oxygen saturation $\leq 92 \%$, whereas $14 \%$ in our study developed an oxygen saturation $\leq 88 \%$. Possible explanations for the differences between studies are the inclusion of participants enrolled at high altitude in COPDGene as well as genetic and racial variations. Despite these differences in study outcomes, Vold et al identified male sex, $\mathrm{FEV}_{1} \leq 50 \%$ predicted, $\geq 10$ packyears smoking history, BMI $\geq 30 \mathrm{~kg} / \mathrm{m}^{2}$, and C-reactive protein $\geq 5 \mathrm{mg} / \mathrm{L}$ as independent predictors of an oxygen saturation decline of $\geq 2 \%$. In another 3-year study of 419 participants with GOLD 2 to 4 stage COPD, Saure and colleagues found no significant change in $\mathrm{P}_{\mathrm{a}} \mathrm{O}_{2}$ over time, but $15 \%$ of the normoxic participants developed at least one episode of hypoxemia [28]. They did not identify any variables predictive of change in $\mathrm{P}_{\mathrm{a}} \mathrm{O}_{2}$.

While the overall change in oxygen saturation was similar between our findings and prior publications, we found that hypoxemia develops in an appreciable portion (7\%) of participants with moderate-to-severe COPD in our cohort. The factors associated with resting hypoxemia are related to lower resting oxygen saturation at baseline, episodic hospitalizations for AECOPD, chronic effects of high altitude, and cardiovascular comorbidities. The major 

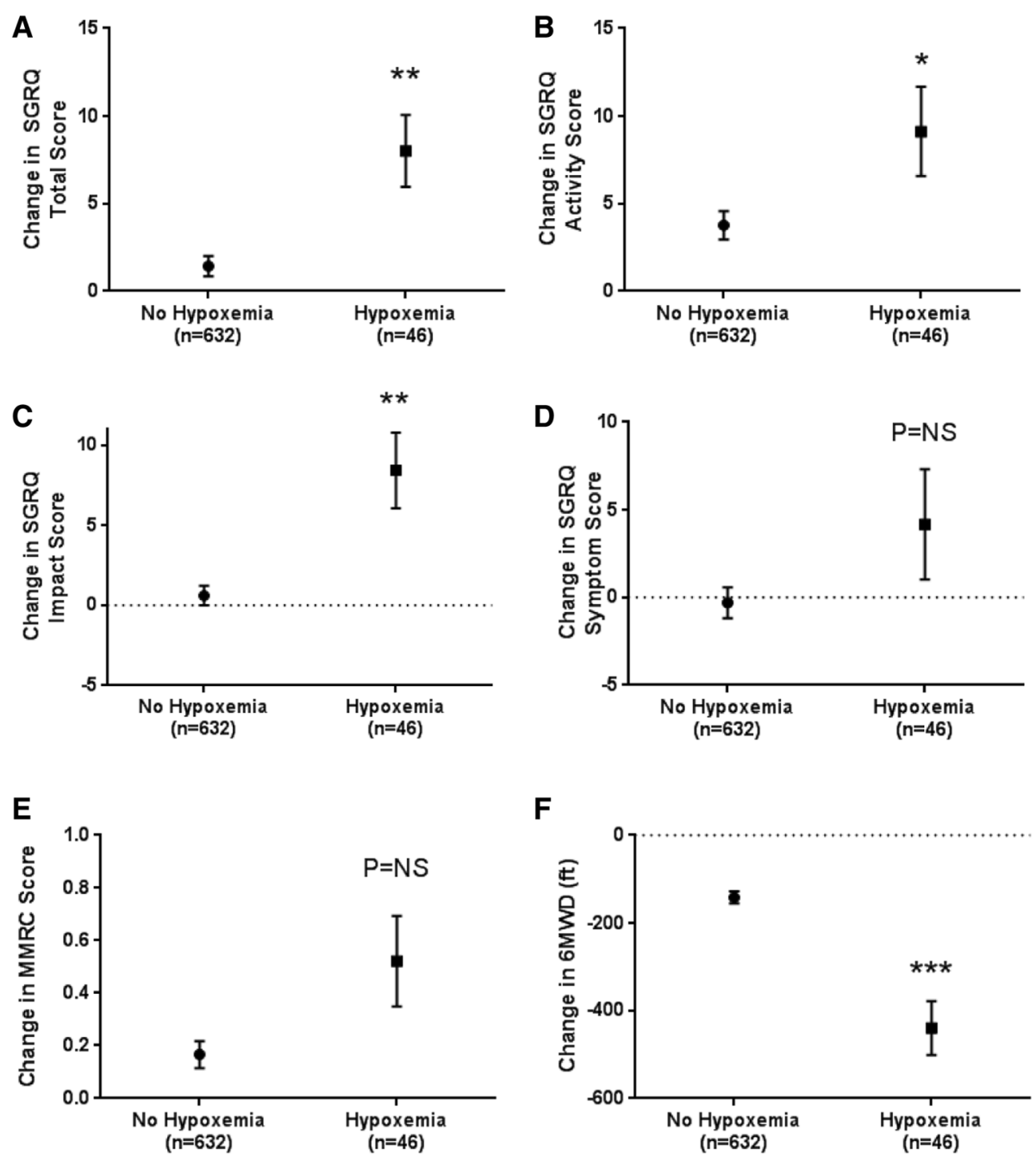

Fig. 3 Development of hypoxemia is associated with worsened QOL and reduced exercise tolerance. Compared to normoxic participants at Phase 2, participants who developed hypoxemia had a greater rate of change in a SGRQ total score, b SGRQ activity score, c SGRQ impact score, but no difference of change in $\mathbf{d}$ SGRQ symptom score or breathlessness measured by e MMRC. Likewise, these participants have a greater decrease in $\mathbf{f} 6 \mathrm{MWD}$ change compared to participants who remained normoxic. Error bars represent standard error. SGRQ $=S t \mathrm{George}$ 's Respiratory Questionnaire, 6MWD =6-min walk distance. MMRC = modified medical research council score. ${ }^{*} P<0.05,{ }^{* *} P<0.01,{ }^{* * *} P<0.001$

contributor to impaired gas exchange in COPD is ventilation/perfusion mismatch due to airflow limitation [29] and emphysematous destruction of the capillary bed [30]. Gas exchange abnormalities present in stable COPD acutely worsen during AECOPD due to effects of inflammation, exaggerated V/Q mismatch, and increased oxygen consumption [31]. Our observations that low $\mathrm{FEV}_{1}$ and previous severe AECOPD contribute to oxygen saturation decline and incident hypoxemia are expected sequelae of these pathophysiologic processes. This leads one to posit the possibility that earlier and more aggressive treatment of underlying lung disease or preventing/minimizing inflammation following AECOPD may forestall the progression of hypoxemia.
Several factors associated with incident hypoxemia and oxygen saturation decline are related to cardiovascular and pulmonary vascular disease. We found that high altitude had the strongest association. It is well established that chronic residence at high altitude is associated with an increased mortality and higher incidence of cor pulmonale in COPD [32, 33]. While short-term studies have been performed evaluating the contribution of altitude on hypoxemia in COPD [34], our findings are the first to report long term changes in oxygen saturation in COPD patients living at high altitude. Given that living in Denver was such a strong independent predictor of the development of hypoxemia in COPD, this might suggest that patients with 
COPD should be advised to move to lower altitudes if these findings are recapitulated in additional studies.

Pulmonary arterial enlargement was the only chest CT metric that was associated with development of hypoxemia. We have previously shown that the PA/A ratio correlates with invasive hemodynamic measurements [35], early right ventricular dysfunction [25], and is predictive of severe AECOPD [26]. Pulmonary arterial enlargement likely represents a common measurable endpoint for the consequences of prolonged exposure to high altitude, ventricular failure, or idiopathic pulmonary hypertension. Although CT emphysema was higher in participants who developed hypoxemia and correlates with follow-up oxygen saturation, it did not independently contribute to oxygen saturation decline. These findings are in agreement with Dournes and colleagues' recent work [36] suggesting that CT metrics of vascular and airway remodeling, but not emphysema, predict oxygen saturation and pulmonary hypertension in COPD. It is possible that other CT metrics not measured in COPDGene, including lung surface area [37] or small vessel volumes $[25,38]$ could also be related to the development of hypoxemia.

We also found a strong association between selfreported $\mathrm{CHF}$ and the development of hypoxemia. Patients with CHF, like those with COPD, depend on hypoxic vasoconstriction to maintain normal gas exchange [39]. While $\mathrm{CHF}$ is not commonly associated with hypoxemia in the absence of other contributing factors, heart failure in the context of cor pulmonale is related to gas exchange abnormalities and hypoxemia in COPD [40]. Consequences of concomitant chronic left ventricular impairment and COPD could be contributory to the development of hypoxemia [41] including residual gas exchange abnormalities stemming from episodic hypoxemia due to heart failure exacerbations [42, 43], intravascular shunting [44], or thromboembolic disease [45].

Incident resting hypoxemia had important implications. Poor quality of life, measured by the SGRQ, is associated with dyspnea, depression, and anxiety, and carries an increased risk for hospitalization and death [46, 47]. Hypoxemia also contributes to worsened SGRQ scores [48], though supplemental oxygen does not improve SGRQ scores in hypoxemic [49] and normoxic patients [50], highlighting the importance of addressing modifiable risk factors to prevent the decline in oxygen saturation. Small studies have shown that long-term supplemental oxygen therapy prevents exercise induced desaturation, improves walk distance, and improves dyspnea $[8,51]$ while others show limited benefit of therapy [52-54]. Clinical equipoise regarding treatment of mild-tomoderate hypoxemia in COPD may be addressed by the results of the upcoming long-term oxygen treatment trial (LOTT) [55].
Our study had several limitations. First, due to the observational nature, we were unable to assign causality between the risk factors identified and development of hypoxemia. Comorbidities were self-reported and may reflect over- or under-representation of comorbid conditions in this COPD cohort. Our study was also limited by the interim data analysis of the first 2000 Phase 2 participants; these results may not be reflective of the entire cohort. Additionally, we used pulse oximetry to assess oxygen saturation as arterial blood gases were not included in the COPDGene study protocol. While arterial blood gas analysis remains the gold standard for measuring oxygen concentration in COPD, pulse oximetry is widely used as a surrogate for evaluating hypoxemia in clinical practice [56, 57], increasing the generalizability of our findings. Finally, oxygen saturations were only measured on two occasions, limiting further conclusions about disease trajectory and raising the question about variability. When Saure and colleagues measured $\mathrm{PaO}_{2}$ at multiple intervals over a 3-year period, they found highly conserved values [28], suggesting that our method and findings are valid.

\section{Conclusions}

Hypoxemia remains a critical development in the natural history of COPD. Our findings provide some insight into the complexities of the development and progression of hypoxemia in moderate to severe COPD and highlight the important contribution that high altitude and cardiovascular disease have on its incidence and may represent additional targets for future interventions.

\section{Additional file}

Additional file 1: Table S1. IRB Approval and Protocol Numbers for COPDGene. (DOCX 26 kb)

\section{Acknowledgements}

The COPDGene investigators thank the individuals who have participated in the study.

\section{Funding}

R01HL089897 and R01HL089856 (to COPDGene); NIH/NHLBI K08HL1123940 (to JMW); R01HL116931, R01HL116473 (RSJE); K01HL118714 (to AAD); R01HL094635, R01HL125583 (CPH). The COPDGene ${ }^{\circledast}$ project is also supported by the COPD Foundation through contributions made to an Industry Advisory Board comprised of AstraZeneca, Boehringer Ingelheim, GlaxoSmithKline, Novartis, Pfizer, Siemens and Sunovion.

Availability of data and material

Available by request

\section{Authors' contributions}

Substantial contributions to the concept and design of the work: JMW, RSJE, $\mathrm{M}-\mathrm{LM}, \mathrm{SPB}, \mathrm{MTD}, \mathrm{RHC}, \mathrm{JDC}, \mathrm{EKS}, \mathrm{CPH}$. Acquisition, analysis, and interpretation of the data: JMW, ML-M, SPB, MTD, RHC, CPH. Drafting and revising the work: all authors (JMW, RSJE, M-LM, SPB, AAD, WCB, FLJ, MTD, GRW, BJM, RC, EJRvB, $E A H, F C S, J D C, E K S, C P H)$. Final approval of the manuscript: all authors (JMW, RSJE, M-LM, SPB, AAD, WCB, FLJ, MTD, GRW, BJM, RC, EJRVB, EAH, FCS, JDC, 
EKS, CPH). JMW is accountable for all aspects of the work in ensuring that questions related to the accuracy or integrity of any part of the work are appropriately investigated and resolved.

\section{Competing interests}

○ JMW - Grants: NIH/NHLBI, Cystic Fibrosis Foundation; Contracts: GSK,

AstraZeneca, Forest; Consulting: AstraZeneca

- RSJE-Grants: NIH/NHLBI

- M-LM-Grants: NIH/NHLBI

- SPB—NIH KL2 Scholarship, 1KL2TR001419

- AAD has received speaker fees from Novartis Inc.

- WCB-none

- FLJ-none

- MTD—Grants: NIH/NHLBI, Department of Defense, Forest, GSK; Contracts:

Aeris, AstraZeneca, Bl, GSK, Pearl, PulmonX, PneumRx, Otsuka, Boston

Scientific, Pfizer; Consulting: BI, Ikaria, GSK

- GRW-none

- BJM-none

- RHC-none

- EVB-is supported by Scottish Imaging Network (SINAPSE).

- EAH-none

- FCS-none

○ JDC - none

- EKS Grants: NIH, GSK; Consulting: GSK, Merck; Honoraria: Novartis, Merck

- CPH Grants: NHH; Consulting: Mylan, Concert Pharmaceuticals, AstraZeneca;

Section Editor for BMC Pulmonary Medicine

\section{Consent for publication}

Not applicable.

\section{Ethics approval and consent to participate}

COPDGene was approved by the Institutional Review Boards at participating institutions (Additional file 1: Table S1, online supplement).

\section{Author details}

'Division of Pulmonary, Allergy, and Critical Care Medicine, University of Alabama Birmingham, Birmingham, AL, USA. ${ }^{2}$ Lung Health Center University of Alabama Birmingham, Birmingham, AL, USA. ${ }^{3}$ Birmingham VA Medical Center, Birmingham, AL, USA. ${ }^{4}$ Department of Radiology, Brigham and Women's Hospital, Boston, MA, USA. ${ }^{5}$ Channing Division of Network Medicine, Brigham and Women's Hospital, Harvard Medical School, Boston, MA, USA. 'Division of Pulmonary Medicine, Brigham and Women's Hospital, Boston, MA, USA. 'Division of Pulmonary, Critical Care, and Sleep Medicine, National Jewish Health, Denver, CO, USA. ${ }^{8}$ Rehabilitation Clinical Trials Center, Los Angeles Biomedical Research Institute at Harbor UCLA Medical Center, Torrance, CA, USA. ${ }^{9}$ Department of Radiology, University of Edinburgh, Edinburgh, Scotland, UK. ${ }^{10}$ Department of Radiology, University of lowa, lowa City, IA, USA. "1 Division of Pulmonary, Allergy, and Critical Care Medicine, University of Pittsburgh, Pittsburgh, PA, USA. ${ }^{12} 1900$ University Blvd, THT 422, Birmingham, AL 35294, USA.

Received: 23 June 2016 Accepted: 22 November 2016

Published online: 01 December 2016

\section{References}

1. Zielinski J, MacNee W, Wedzicha J, Ambrosino N, Braghiroli A, Dolensky J, Howard P, Gorzelak K, Lahdensuo A, Strom K, et al. Causes of death in patients with COPD and chronic respiratory failure. Monaldi Arch Chest Dis. 1997;52(1):43-7.

2. Antonucci R, Berton E, Huertas A, Laveneziana P, Palange P. Exercise physiology in COPD. Monaldi Arch Chest Dis. 2003;59(2):134-9.

3. Chaouat A, Naeije R, Weitzenblum E. Pulmonary hypertension in COPD. Eur Respir J. 2008;32(5):1371-85.

4. Kim HC, Mofarrahi M, Hussain SN. Skeletal muscle dysfunction in patients with chronic obstructive pulmonary disease. Int J Chron Obstruct Pulmon Dis. 2008;3(4):637-58.

5. Vanier T, Dulfano J, Wu C, Desforges JF. Emphysema, hypoxia and the polycthemic response. N Engl J Med. 1963;269:169-78.

6. Andrianopoulos V, Franssen FM, Peeters JP, Ubachs TJ, Bukari H, Groenen M, Burtin C, Vogiatzis I, Wouters EF, Spruit MA. Exercise-induced oxygen desaturation in COPD patients without resting hypoxemia. Respir Physiol Neurobiol. 2014:190:40-6.

7. Andrianopoulos V, Wouters EF, Pinto-Plata VM, Vanfleteren LE, Bakke PS, Franssen FM, Agusti A, MacNee W, Rennard SI, Tal-Singer R, et al. Prognostic value of variables derived from the six-minute walk test in patients with COPD: Results from the ECLIPSE study. Respir Med. 2015;109(9):1138-46.

8. Jolly EC, Di Boscio V, Aguirre L, Luna CM, Berensztein S, Gene RJ. Effects of supplemental oxygen during activity in patients with advanced COPD without severe resting hypoxemia. Chest. 2001;120(2):437-43.

9. Lewis CA, Fergusson W, Eaton T, Zeng I, Kolbe J. Isolated nocturnal desaturation in COPD: prevalence and impact on quality of life and sleep. Thorax. 2009;64(2):133-8.

10. Centers for Medicare and Medicaid Services. National Coverage Determinations for Home Use of Oxygen Section 240.2 Publication Number 100-3 1993, https://www.cms.gov/medicare-coverage-database/details/ncddetails.aspx?NCDId=169\&ncdver=1\&DocID=240.2. Accessed Dec 2015.

11. Chan ED, Chan MM, Chan MM. Pulse oximetry: understanding its basic principles facilitates appreciation of its limitations. Respir Med. 2013:107(6):789-99.

12. Cranston JM, Crockett AJ, Moss JR, Alpers JH. Domiciliary oxygen for chronic obstructive pulmonary disease. Cochrane Database Syst Rev. 2005:4:CD001744.

13. Flenley DC. Long-Term Domiciliary Oxygen-Therapy in Chronic Hypoxic CorPulmonale Complicating Chronic-Bronchitis and Emphysema. Lancet. 1981;1(8222):681-6.

14. Nocturnal Oxygen Therapy Trial Group. Continuous or nocturnal oxygen therapy in hypoxemic chronic obstructive lung disease: a clinical trial. Ann Intern Med. 1980;93(3):391-8.

15. Eaton $T$, Lewis C, Young P, Kennedy Y, Garrett JE, Kolbe J. Long-term oxygen therapy improves health-related quality of life. Respir Med. 2004;98(4):285-93.

16. Kim DK, Jacobson FL, Washko GR, Casaburi R, Make BJ, Crapo JD, Silverman EK, Hersh CP. Clinical and radiographic correlates of hypoxemia and oxygen therapy in the COPDGene study. Respir Med. 2011;105(8):1211-21.

17. Regan EA, Hokanson JE, Murphy JR, Make B, Lynch DA, Beaty TH, CurranEverett D, Silverman EK, Crapo JD. Genetic epidemiology of COPD (COPDGene) study design. COPD. 2010:7(1):32-43.

18. Vestbo J, Hurd SS, Agusti AG, Jones PW, Vogelmeier C, Anzueto A, Barnes PJ, Fabbri LM, Martinez FJ, Nishimura M, et al. Global strategy for the diagnosis, management, and prevention of chronic obstructive pulmonary disease: GOLD executive summary. Am J Respir Crit Care Med. 2013;187(4):347-65.

19. Miller MR, Hankinson J, Brusasco V, Burgos F, Casaburi R, Coates A, Crapo R, Enright $P$, van der Grinten CP, Gustafsson P, et al. Standardisation of spirometry. Eur Respir J. 2005;26(2):319-38.

20. Laboratories ATSCOPSFCPF. ATS statement: guidelines for the six-minute walk test. Am J Respir Crit Care Med. 2002;166(1):111-7.

21. Jones PW, Quirk FH, Baveystock CM, Littlejohns P. A self-complete measure of health status for chronic airflow limitation. The St. George's Respiratory Questionnaire. Am Rev Respir Dis. 1992;145(6):1321-7.

22. Mahler DA, Wells CK. Evaluation of clinical methods for rating dyspnea. Chest. 1988;93(3):580-6.

23. Gevenois PA, de Maertelaer V, De Vuyst P, Zanen J, Yernault JC. Comparison of computed density and macroscopic morphometry in pulmonary emphysema. Am J Respir Crit Care Med. 1995;152(2):653-7.

24. Busacker A, Newell Jr JD, Keefe T, Hoffman EA, Granroth JC, Castro M, Fain S, Wenzel S. A multivariate analysis of risk factors for the air-trapping asthmatic phenotype as measured by quantitative CT analysis. Chest. 2009;135(1):48-56.

25. Wells JM, lyer AS, Rahaghi FN, Bhatt SP, Gupta H, Denney TS, Lloyd SG, Dell'Italia $L$, Nath $H$, Estepar RS et al. Pulmonary artery enlargement is associated with right ventricular dysfunction and loss of blood volume in small pulmonary vessels in chronic obstructive pulmonary disease. Circ Cardiovasc Imaging. 2015;8(4). doi:10.1161/CIRCIMAGING.114.002546.

26. Wells JM, Washko GR, Han MK, Abbas N, Nath H, Mamary AJ, Regan E, Bailey WC, Martinez FJ, Westfall E, et al. Pulmonary arterial enlargement and acute exacerbations of COPD. N Engl J Med. 2012;367(10):913-21.

27. Vold ML, Aasebo U, Hjalmarsen A, Melbye H. Predictors of oxygen saturation $</=95 \%$ in a cross-sectional population based survey. Respir Med. 2012; 106(11):1551-8.

28. Saure EW, Eagan TM, Jensen RL, Bakke PS, Johannessen A, Aanerud M, Nilsen RM, Thorsen E, Hardie JA. Predictors for $\mathrm{PaO} 2$ and hypoxemic respiratory failure in COPD-A three-year follow-up. COPD. 2014;11(5):531-8. 
29. Rodriguez-Roisin R, Drakulovic M, Rodriguez DA, Roca J, Barbera JA, Wagner PD. Ventilation-perfusion imbalance and chronic obstructive pulmonary disease staging severity. J Appl Physiol (1985). 2009;106(6):1902-8.

30. Martin HB, Boatman ES. Electron microscopy of human pulmonary emphysema. Am Rev Respir Dis. 1965;91:206-14.

31. Barbera JA, Roca J, Ferrer A, Felez MA, Diaz O, Roger N, Rodriguez-Roisin R. Mechanisms of worsening gas exchange during acute exacerbations of chronic obstructive pulmonary disease. Eur Respir J. 1997;10(6):1285-91.

32. Cote TR, Stroup DF, Dwyer DM, Horan JM, Peterson DE. Chronic obstructive pulmonary disease mortality. A role for altitude. Chest. 1993;103(4):1194-7.

33. Moore LG, Rohr AL, Maisenbach JK, Reeves $\pi$. Emphysema mortality is increased in Colorado residents at high altitude. Am Rev Respir Dis. 1982;126(2):225-8.

34. Luks AM, Swenson ER. Travel to high altitude with pre-existing lung disease. Eur Respir J. 2007;29(4):770-92.

35. Iyer AS, Wells JM, Vishin S, Bhatt SP, Wille KM, Dransfield MT. CT scan-measured pulmonary artery to aorta ratio and echocardiography for detecting pulmonary hypertension in severe COPD. Chest. 2014;145(4):824-32.

36. Dournes G, Laurent F, Coste F, Dromer C, Blanchard E, Picard F, Baldacci F, Montaudon M, Girodet PO, Marthan R, et al. Computed tomographic measurement of airway remodeling and emphysema in advanced chronic obstructive pulmonary disease. Correlation with pulmonary hypertension. Am J Respir Crit Care Med. 2015;191(1):63-70.

37. Coxson HO, Rogers RM, Whittall KP, D'Yachkova Y, Pare PD, Sciurba FC, Hogg JC. A quantification of the lung surface area in emphysema using computed tomography. Am J Respir Crit Care Med. 1999;159(3):851-6.

38. Estepar RS, Kinney GL, Black-Shinn JL, Bowler RP, Kindlmann GL, Ross JC, Kikinis R, Han MK, Come CE, Diaz AA, et al. Computed tomographic measures of pulmonary vascular morphology in smokers and their clinical implications. Am J Respir Crit Care Med. 2013;188(2):231-9.

39. Robertson HT. Gas exchange consequences of left heart failure. Compr Physiol. 2011;1(2):621-34

40. Levin DL, Muster AJ, Pachman LM, Wessel HU, Paul MH, Koshaba J. Cor pulmonale secondary to upper airway obstruction. Cardiac catheterization, immunologic, and psychometric evaluation in nine patients. Chest. 1975;68(2):166-71.

41. Bhatt SP, Dransfield MT. Chronic obstructive pulmonary disease and cardiovascular disease. Transl Res. 2013;162(4):237-51.

42. Fillmore SJ, Shapiro M, Killip T. Arterial oxygen tension in acute myocardial infarction. Serial analysis of clinical state and blood gas changes. Am Heart J. 1970;79(5):620-9.

43. Light RW, George RB. Serial pulmonary function in patients with acute heart failure. Arch Intern Med. 1983;143(3):429-33.

44. Clark AL, Coats AJ. Usefulness of arterial blood gas estimations during exercise in patients with chronic heart failure. Br Heart J. 1994;71(6):528-30.

45. Piazza G, Goldhaber SZ. Pulmonary embolism in heart failure. Circulation. 2008;118(15):1598-601.

46. Hurst JR, Vestbo J, Anzueto A, Locantore N, Mullerova H, Tal-Singer R, Miller B, Lomas DA, Agusti A, Macnee W, et al. Susceptibility to exacerbation in chronic obstructive pulmonary disease. N Engl J Med. 2010;363(12):1128-38.

47. Almagro P, Calbo E, Ochoa de Echaguen A, Barreiro B, Quintana S, Heredia JL, Garau J. Mortality after hospitalization for COPD. Chest. 2002;121(5):1441-8.

48. Okubadejo AA, Jones PW, Wedzicha JA. Quality of life in patients with chronic obstructive pulmonary disease and severe hypoxaemia. Thorax. 1996;51(1):44-7.

49. Okubadejo AA, Paul EA, Jones PW, Wedzicha JA. Does long-term oxygen therapy affect quality of life in patients with chronic obstructive pulmonary disease and severe hypoxaemia? Eur Respir J. 1996;9(11):2335-9.

50. Ringbaek T, Martinez G, Lange $P$. The long-term effect of ambulatory oxygen in normoxaemic COPD patients: a randomised study. Chron Respir Dis. 2013;10(2):77-84

51. Bradley JM, O'Neill B. Short-term ambulatory oxygen for chronic obstructive pulmonary disease. Cochrane Database Syst Rev. 2005;4:CD004356.

52. McDonald CF, Blyth CM, Lazarus MD, Marschner I, Barter CE. Exertional oxygen of limited benefit in patients with chronic obstructive pulmonary disease and mild hypoxemia. Am J Respir Crit Care Med. 1995;152(5 Pt 1):1616-9.

53. Uronis H, McCrory DC, Samsa G, Currow D, Abernethy A. Symptomatic oxygen for non-hypoxaemic chronic obstructive pulmonary disease. Cochrane Database Syst Rev. 2011;6:CD006429.

54. Nonoyama ML, Brooks D, Lacasse Y, Guyatt GH, Goldstein RS. Oxygen therapy during exercise training in chronic obstructive pulmonary disease. Cochrane Database Syst Rev. 2007;2:CD005372
55. Stoller JK, Panos RJ, Krachman S, Doherty DE, Make B, Long-term Oxygen Treatment Trial Research G. Oxygen therapy for patients with COPD: current evidence and the long-term oxygen treatment trial. Chest. 2010;138(1):179-87.

56. Roberts CM, Bugler JR, Melchor R, Hetzel MR, Spiro SG. Value of pulse oximetry in screening for long-term oxygen therapy requirement. Eur Respir J. 1993;6(4):559-62.

57. Hanning CD, Alexander-Williams JM. Pulse oximetry: a practical review. BMJ. 1995:311(7001):367-70

\section{Submit your next manuscript to BioMed Central and we will help you at every step:}

- We accept pre-submission inquiries

- Our selector tool helps you to find the most relevant journal

- We provide round the clock customer support

- Convenient online submission

- Thorough peer review

- Inclusion in PubMed and all major indexing services

- Maximum visibility for your research

Submit your manuscript at www.biomedcentral.com/submit
) Biomed Central 